\title{
Amplification of root-fungus interface in ectomycorrhizae by Hartig net architecture
}

\section{Kottke and F. Oberwinkler}

Universität Tübingen, Institut für Botanik, Spezielle Botanik und Mykologie, Tübingen. F.R.G.

\section{Introduction}

In previous investigations, it was found that the Hartig net is formed quite similarly in ectomycorrhizae of different fungal species with diverse trees, despite characteristic differences in mantle structure (Mangin, 1910; Blasius et al., 1986; Kottke and Oberwinkler, 1986; Haug, 1987). The question arose whether there was any functional benefit for the development of the observed Hartig net architecture imposing evolutionary pressure to equalize the development in different mycorrhizal types.

Transmission electron microscopy studies revealed that the scarce septation and the intimate juxtaposition of the hyphae result in a transfer cell-like structure of the Hartig net, amplifying the intersymbiont surface (Fig. 1; Kottke and Oberwinkler, 1987). Hyphae do not penetrate separately but as a lobed front between the cortical cells. The tips of the fan-like branched hyphal system are characterized by a large number of mitochondria and high amounts of rough endoplasmic reticulum. Cytoplasm in this region contains many ribosomes and lacks large vacuoles. The hind parts of the hyphae become dilated but remain in close contact with the surface of the cortical cells. These characteristics can be found when the Hartig net is in an active state. The bidirectional active exchange of solutes between fungus and root is underlined by the results obtained from cytochemical proof of ATPase activities at this stage (Lei and Dexheimer, 1988). In ageing mycorrhizae, cortical cells are the first to die and their active uptake of solutes is no longer possible. At this stage, hyphae of the Hartig net can

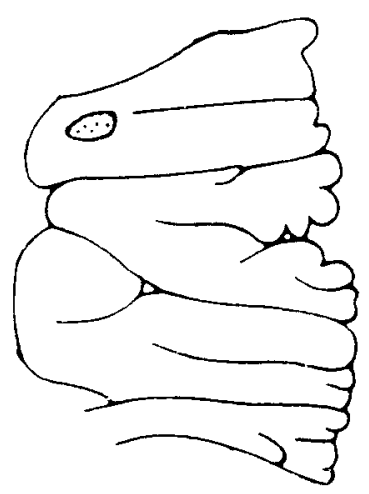

Fig. 1. Characteristics of Hartig nel tyyplicte? lober front, frequently branched. scarcely septate in close contact 


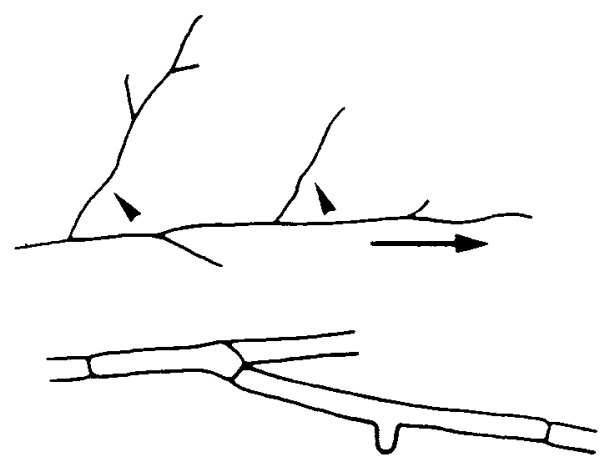

Fig. 2. Characteristics of hyphal growth on solid surfaces: apical dominance of leading hypha, scarce branching linked with septation, negative autotropism between main hyphae and hyphal branches. (Suillus grevillei on agar plate.)

frequently be found separated from each other.

Hyphal growth of an active Hartig net is totally different from hyphal growth on solid surfaces, e.g., agar media. Hyphal growth on agar media shows apical dominance of the parent hyphae, regular, but not too frequent branching in correlation to septation, and negative autotropism between neighboring hyphae (Trinci, 1984; Prosser, 1983). The result is a pinnate growth of scattered hyphae, spreading quickly over a large surface (Fig. 2). It is also well documented that, in fungal colonies, only the hyphal tips contain dense cytoplasm, whereas the other parts of the hyphal system are highly vacuolated. Although regulators are still unknown, the strongly modified growth pattern of hyphae with Hartig net formation is most probably elicited by the cortical cells. It is therefore presumed, that the growth pattern is beneficial for the cortical cells as well as for the fungus. By modeling we try to show that the Hartig net architecture is the most effective only as long as bidirectional transport of solutes is assumed.

\section{Materials and Methods}

Models were delineated from micrographs of the Hartig net and from possible alternatives in growth of hyphae (Fig. 3). Area, perimeter and length of hyphal walls of the models were measured with Mop-Videoplan, an analytic system (Zeiss-Kontron), using standard software. The surface/volume ratios of the different systems were calculated on the basis of an average 3 $\mu \mathrm{m}$ diameter of hyhae.

\section{Results}

Three different models of hyphal growth in the intercellular spaces have been designed (Fig. 3a, b, c) and the surface/ volume ratio of hyphae calculated. The first model is delineated from the real occurring Hartig net structure, the second from presumed broadly dilated hyphae and the third from presumed separately growing hyphae. Measurements from these models of area and perimeter of hyphal complex and length of hyphal walls are presented in Table I.

The results show that the surface/ volume ratio of the fungus is the best, when hyphae grow separately through the intercellular space. However, the hyphal area in close contact with the cortical cell is considerably larger with broadly dilated hyphae. The surface of dilated hyphae is again enlarged by compartmentation into Hartig net lobes.

It can be concluded from the calculation of the surface/volume ratio that the lobed Hartig net structure is only the most favorable as long as an active bidirectional transport is present. When hyphae take up ions and molecules from the intercellular space, the absorptive surface of hyphae is larger with free, separately penetrating hyphae, a structure that can be observed after the death of cortical cells, when active absorption is restricted to the 


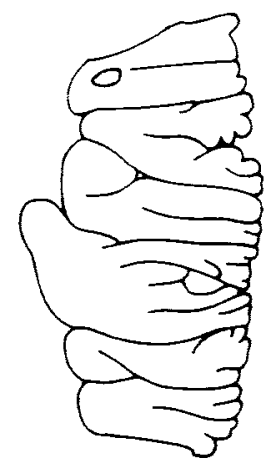

a

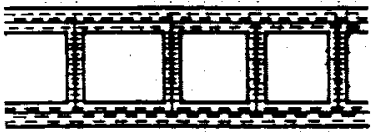

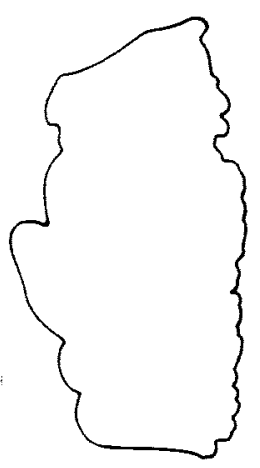

b

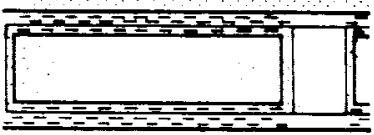

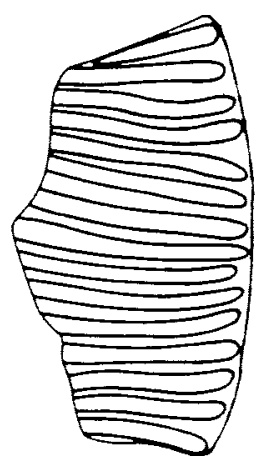

C

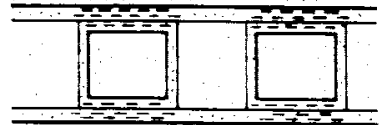

Fig. 3. Models of conceivable hyphal growth through the intercellular spaces. Tap panel: topviews; bottom panel: transverse sections of the intercellular space. a: delineated from real Hartig net structure; b: presumed broadly dilated hyphae; $c$ : presumed separately growing hyphae; dashes indicate a zone of bidirectional transport; fine dots indicate zones of absorption by hyphae only. Area, perimeter of hyphae and length of hyphal walls were measured on these models with Mop-Videoplan (Table I).

fungus. The intimate contact with the cell surface and the transfer cell-like structure of the Hartig net must therefore be considered as not only promoting absorption by but also releasing solutes from the fungus. The solute efflux may be active or by leakage. Cytokinins secreted by the tree root may influence ion release (Pohleven, 1988). Transport to the cortical cell walls can easily occur as there seems to be no physical barrier to ion or molecule diffusion between the cell walls of the fungus and the cortex. A greater outtlow of solutes from the hyphae will thus enable

Table I. Parameters of hyphal growth for 3 models.

\begin{tabular}{lccc}
\hline Parameter & $\begin{array}{l}\text { Hartig net } \\
\text { structure }\end{array}$ & $\begin{array}{l}\text { Dilated } \\
\text { hyphae }\end{array}$ & $\begin{array}{l}\text { Free } \\
\text { hyphae }\end{array}$ \\
\hline Area $\left(\mu \mathrm{m}^{2}\right)$ & 532 & 532 & 264 \\
Perimeter $(\mu \mathrm{m})$ & 647 & 647 & 1172 \\
Length of walls $(\mu \mathrm{m})$ & 1022 & 647 & 1172 \\
Volume $\left(\mu \mathrm{m}^{3}\right)$ & 1596 & 1596 & 793 \\
Surfaceb $^{\mathrm{b}}\left(\mu \mathrm{m}^{2}\right)$ & 4131 & 2979 & 3986 \\
Surface $/$ volume & 2.6 & 1.9 & 5.0 \\
ratio & & & \\
\hline
\end{tabular}

a Calculated from covered area and a height of $3 \mu \mathrm{m}$ for all models.

b Calculated from the total length of hyphal walls and a height of $3 \mu \mathrm{m}$ added to 2 times the area. 
an easier uptake by the cortical cells, although the plasmalemma of the cortical cells is not enlarged.

\section{Acknowledgments}

The investigations have been supported by grants from the Deutsche Forschungsgemeinschaft and the Projekt Europäisches Forschungszentrum.

\section{References}

Blasius D., Feil W., Kottke I. \& Oberwinkler F. (1986) Hartig net structure and formation in fully ensheathed ectomycorrhizas. Nord. J. Bot. 6 , $837-842$

Haug I. (1987) Licht- und elektronenmikroskopische untersuchungen an mykorrhizen von fichtenbeständen im Schwarzwald. PhD. dissertation, Tübingen, F.R.G.
Kottke I. \& Oberwinkler F. (1986) Mycorrhiza of forest trees - structure and function. Trees 1, 124

Kottke 1. \& Oberwinkler F. (1987) Cellular structure and function of the Hartig net: coenocytic and transfer cell-like organization. Nord. J. Bot. 7, 85-95

Lei J. \& Dexheimer J. (1988) Ultrastructural localization of ATPase activity in the Pinus sy/vestris/Laccaria laccata ectomycorrhizal association. New Phytol. 108, 329-334

Mangin L. (1910) Introduction à l'étude des mycorhizes des arbres forestiers. Nouv. Arch. Mus. Hist. Nat. 5 Sér 2, 245-276

Pohleven F. (1988) The influence of cylokinin 2i $P A$ on growth, ion transport and membrane fluidity in mycelia of the mycorrhizae fungus Suillus variegatus. 2nd European Symposium on mycorrhizae, 14-20 August 1988. Abstr. 80

Prosser J.I. (1983) Hyphal growth patterns. In: Fungal Differentiation: a Contemporary Synthesis (Smith E., ed.). Mycol. Ser. Vol. 4. Marcel Dekker, New York, pp. 357-396

Trinci A.P. (1984) Regulation of hyphal branching and hyphal orientation. In: The Ecology and Physiology of the Fungal Mycelium (Jennings D.H. \& Rayner A.D., eds.). Symp. Br. Mycol. Soc. 1983. Cambridge University Press, Cambridge, pp. 23-52 